\title{
Frailty In Patients Undergoing Vascular Surgery: A Narrative Review Of Current Evidence
}

This article was published in the following Dove Press journal:

Therapeutics and Clinical Risk Management

\author{
Nikoletta Rahel Czobor (D) ${ }^{1,2}$ \\ Jean-Jacques Lehot ${ }^{3,4}$ \\ Eniko Holndonner-Kirst (D) \\ Phillip J Tully ${ }^{5}$ \\ Janos Gal $\mathbb{D}^{6}$ \\ Andrea Szekely $\mathbb{D}^{6,7}$
}

'Medical Centre of Hungarian Defense Forces, Department of Anesthesiology and Intensive Care, Budapest, Hungary; ${ }^{2}$ Semmelweis University, School of Doctoral Studies, Budapest, Hungary;

${ }^{3}$ Claude-Bernard University, Health Services and Performance Research Lab (EA 7425 HESPER), Lyon, France; ${ }^{4}$ Hôpital Neurologique Pierre Wertheimer, Department of Neuroanesthesia and Intensive Care, Hospices Civils de Lyon, Lyon, France; ${ }^{5}$ University of Adelaide, Freemasons Foundation Centre for Men's Health, Adelaide, Australia; ${ }^{6}$ Semmelweis University, Department of Anesthesiology and Intensive Care, Budapest, Hungary; ${ }^{7}$ Semmelweis University, Heart and Vascular Center of Városmajor, Budapest, Hungary
Correspondence: Andrea Szekely Department of Anaesthesiology and Intensive Therapy, Semmelweis University, Üllöi út 78, Budapest 1082, Hungary Tel +36206632243

Email andi_szekely@yahoo.com

\begin{abstract}
Frailty is presumably associated with an elevated risk of postoperative mortality and adverse outcome in vascular surgery patients. The aim of our review was to identify possible methods for risk assessment and prehabilitation in order to improve recovery and postoperative outcome. The literature search was performed via PubMed, Embase, OvidSP, and the Cochrane Library. We collected papers published in peer-reviewed journals between 2001 and 2018. The selection criterion was the relationship between vascular surgery, frailty and postoperative outcome or mortality. A total number of 52 publications were included. Frailty increases the risk of non-home discharge independently of presence or absence of postoperative complications and it is related to a higher 30-day mortality and major morbidity. The modified Frailty Index showed significant association with elevated risk for postinterventional stroke, myocardial infarction, prolonged in-hospital stays and higher readmission rates. When adjusted for comorbidity and surgery type, frailty seems to impact medium-term survival (within 2 years). Preoperative physical exercising, avoidance of hypalbuminemia, psychological and cognitive training, maintenance of muscle strength, adequate perioperative nutrition, and management of smoking behaviours are leading to a reduced length of stay and a decreased incidence of readmission rate, thus improving the effectiveness of early rehabilitation. Pre-frailty is a dynamically changing state of the patient, capable of deteriorating or improving over time. With goal-directed preoperative interventions, the decline can be prevented.
\end{abstract}

Keywords: preoperative risk assessment, postoperative outcome, patient management, prehabilitation

\section{Background}

Thanks to the continuous development of surgical and anaesthetic techniques, patient-related factors have become another important focus of interest in the preoperative risk assessment. The introduction and use of physiological and surgical risk assessment systems, like the American Society of Anaesthesiology classification $(\mathrm{ASA})^{1}$ and the Vascular POSSUM system (Physiologic and Operative Severity Score for the enUmeration of Mortality and morbidity), ${ }^{2,3}$ led to an easier decision-making process compared to the previous decades. The POSSUM scoring system predicts the risk for operative morbidity and mortality for patients undergoing surgery. It is divided into two parts: the first includes physiological variables from the preoperative period; the second contains data registered during the intraand postoperative periods. The model includes 12 variables examining the clinical symptoms of each patient and the results of medical examinations, as well as laboratory and hematologic findings and electrocardiographic examinations. The 
POSSUM in summary analyses the outcome and complications of morbidity. ${ }^{2,4}$ For vascular procedures, V-POSSUM equations (Physiology and operative, and physiology only) were developed by the Vascular Surgical Society of Great Britain and Ireland (VSSGBI). The scoring method is based on the operative outcome of this special patient population. ${ }^{5}$

Despite these well-developed stratification systems, the clinical experience shows that there must be other, presumably functional, social and psychological features influencing the postoperative outcome that have not been evaluated by the routinely used physiological prognostic systems. Behavioural maladaptation evolves in two different ways. First, it is due to irreversible individual and internal factors, like age-related physiological and psychological changes (deconditioning, loss of physiological capacity and reserve), disease burden or mental-health limitations. Second, it is due to the effect of the external influencers, like the environmental support (family and social networks), having a large extent in the development of frailty syndrome. ${ }^{6}$ This latter is considered the most variable and improvable of the causative effects.

A good example for simultaneous application of physiological and psychological characteristics is the DSM-V criteria (Fifth edition of the Diagnostic and Statistical Manual of Mental Disorders published by the American Psychiatric Association), ${ }^{7}$ which primarily used to categorize mental disorders but it is also considering the physical health condition of the patients. The system is based on the principle that psychological and physical states should always be analysed together. The DSM-IV contains five different axes: axis I and axis II are including mental and psychiatric disorders, axis III is including the general medical condition, axis IV is containing psychosocial and environmental factors contributing to the disorder and axis V stands for the Global Assessment of Functioning. ${ }^{7}$ The diagnosis of psychiatric disorders is multifactorial and the physical functioning itself can be either the cause or the consequence of these diseases. Considering this, the separate analysis of psychological and physiological vulnerabilities in the daily clinical routine may be misleading, especially when facing a patient with frailty syndrome. Several systematic reviews and meta-analyses are available regarding the assessment and the perioperative management of frail individuals, ${ }^{8-10}$ but none of them is limited to vascular surgery patients.

The aim of our review was to summarize the current evidence in the literature regarding the impact of frailty on the outcome following vascular surgery and to collect the possibilities of risk assessment and prehabilitation in order to improve recovery and postoperative outcome.

\section{Methods}

We proceeded with a literature review to identify papers examining the impact of frailty on the postoperative outcome in the field of vascular surgeries. The research was performed via the Internet (PubMed; Embase; OvidSP and the Cochrane Library were used). The literature research process is presented in Figure 1. Major selection criteria were: the relationship between vascular surgery and postoperative outcome or mortality; the impacts of preoperative interventions or risk assessment tools and postoperative outcome or recovery. We included articles reporting data of patients undergoing elective vascular interventions of the following types: endovascular and open repair of abdominal aortic aneurysms; endovascular repair of thoracic aortic aneurysms; thoracic aortic dissections and thoracoabdominal aneurysms; open surgical reconstructions; balloon angioplasty or stenting in all vascular areas; bypass surgeries for peripheral artery diseases of the limbs; carotid endarterectomy and carotid artery stenting; surgical reconstructions for deep vein occlusions. Risk levels for vascular procedures were defined according to the occurrence of cardiac events defined by the European Society of Cardiology and Anesthesiology (ESC/ESA) 2014 Guidelines: low-risk - cardiac complication rate $<1 \%$ (superficial venous interventions, carotid artery stenting); intermediate risk - cardiac complication rate $1-5 \%$ (carotid endarterectomies, peripheral arterial angioplasty, endovascular aneurysm repair) and high risk - cardiac complication rate $>5 \%$ (aortic and major vascular surgery, open lower limb revascularization or thromboembolectomy). ${ }^{11}$ We defined a time-interval between January 1st 2001 and December 30th 2018 and we evaluated publications fulfilling all the following criteria: (a) was published in a peer-reviewed journal in English between, 2018; (b) dealt with adult patients undergoing vascular surgery and reported outcome results in relationship with frailty (including cognitive dysfunction and quality-of-life); and (c) reported a statistically significant reduction or increase in short-, or long-term complication or mortality. Most important keywords were searched in relation to: frailty; frailty-syndrome; vascular surgery; mortality; short-term and long-term outcome; postoperative outcome; risk assessment; prehabilitation; perioperative management. Major complications described in the studies were: pulmonary (need for long-term mechanical ventilation, acute respiratory failure or acute respiratory distress 


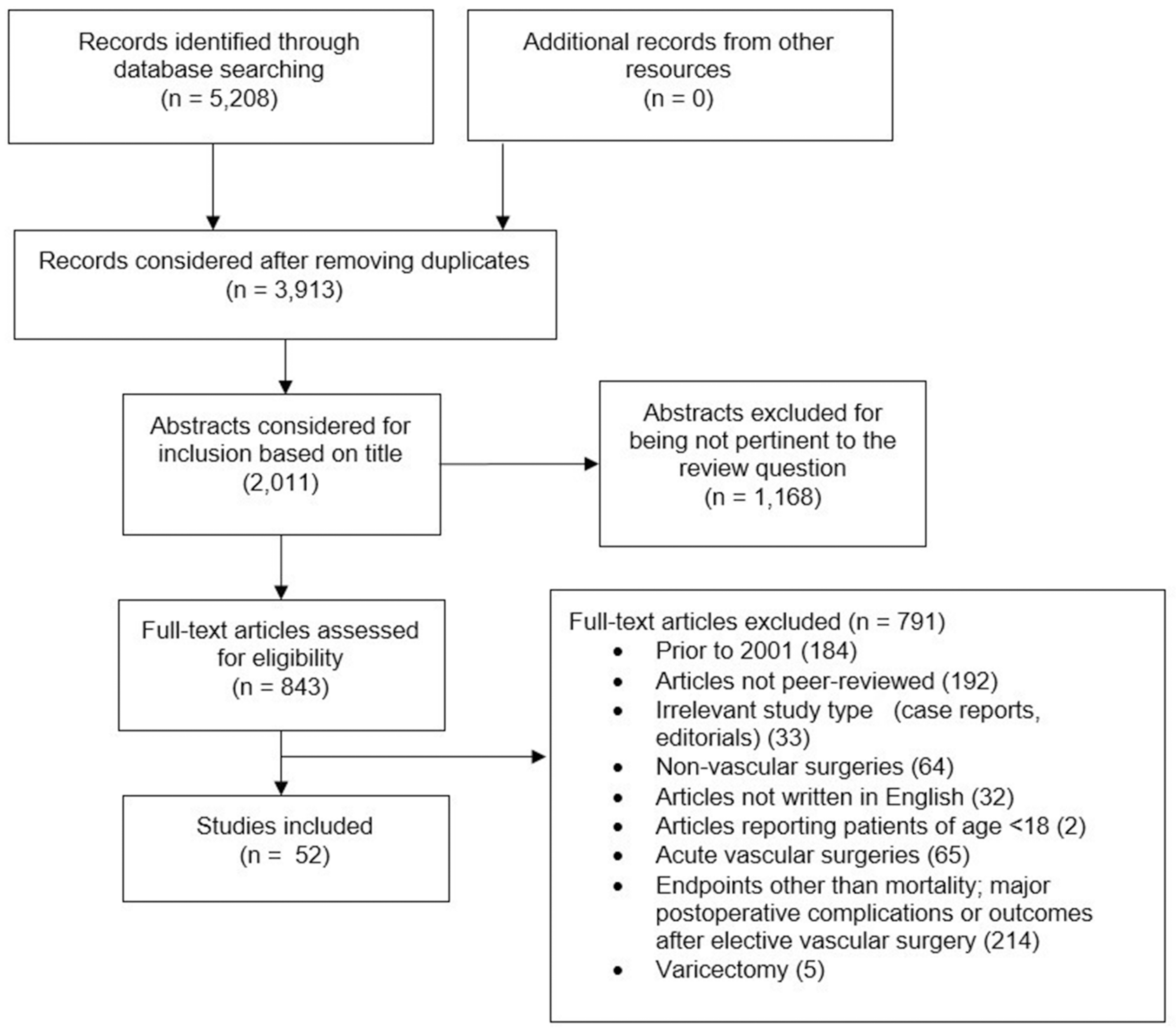

Figure I Flow chart of literature research process

Note: PRISMA format used. ${ }^{108}$

syndrome (ARDS)); circulatory (acute heart failure, arrhythmias, need for inotropic support, peripheral circulatory failure); neurological (cerebrovascular events); infective complications; acute kidney injury (need for renal replacement therapy) and surgical complications (bleeding, reoperations due to graft failure or suture insufficiency).

Articles were excluded if the primary endpoint was other than postoperative outcome and/or mortality. We also excluded case-control and case report studies, papers reporting patients under 18 years of age and papers dealing with adult patients undergoing electrophysiological interventions (radiofrequency ablation - RFA, pacemaker implantation, etc.), varicectomy or cardiac surgery.

\section{Results}

A total number of 52 publications were included. We aimed to summarize the findings actually available about the perioperative management of frail patients in the field of vascular surgery.

\section{Frailty}

The proportion of elderly patients is high in vascular surgery, since atherosclerosis, the underlying cause of several vascular diseases, progresses with time. Factors such as comorbidities, functional reserve, dependence in daily activities and gait parameters are better predictors of surgical outcome than the age per se. Vascular surgeons and anesthesiologists face the challenge to evaluate the 
biological, rather than chronological, age of their patients' during preoperative risk assessment. ${ }^{12,13}$

The term of frailty was established by Vapuel in $1979 .{ }^{14}$ Besides geriatric usage, it was rapidly adopted and integrated into the clinical decision-making process. The concept of frailty defines a multidimensional decline of the aging individual that results in an increased vulnerability. ${ }^{15}$ There is a homeostenosis in frail patients, which means that they cannot maintain homeostasis required for even moderate-risk surgical situations. ${ }^{16}$ In addition to this theoretical definition, efforts have been made to establish a more objective and measurable framework. Two different but not necessarily exclusive models have been created: the Phenotypic $^{17}$ and the Accumulating Deficits Model. ${ }^{18}$

The Phenotypic Model of Fried et al focuses on patient characteristic across five domains: unintentional weight loss, slow gait speed, self-reported exhaustion, impaired grip strength and low physical activity. Patients presenting three or more of these symptoms are considered "frail", those with 1 or 2 positive tests are defined as "pre-frails", while "stronger" individuals have the score of zero. ${ }^{17}$

The Canadian Study of Health and Aging defined frailty as the balance of deficits and assets: 70 different physical, mental, medical and functional problems are examined as part of the Comprehensive Geriatric Assessment. Frailty Index (FI) is calculated as the number of positive items divided by 70 (number of all items). If the FI is over 0.5 , then "Frailty" is present. ${ }^{18}$ This method evaluates accurately the frailty level of patients, but it is too time-consuming to use in clinical routine.

While a consensus has been reached on the elements of frailty and the five physical domains of Fried, supplemented by mental and cognitive domains, the clear operational definition and the most effective clinically applicable version is not yet established. ${ }^{19}$ In the same time, the definition of "physical frailty" has been refined:

A medical syndrome, with multiple causes and contributors that is characterized by diminished strength, endurance and reduced physiological function that increases an individual's vulnerability for developing increased dependency and/or death. ${ }^{20}$

There are several mechanisms that might be related to frailty such as inflammation, coagulation, oxidative stress and agerelated modification of hormonal pathways. Altered function of the hypothalamic-pituitary-adrenal (HPA) or -testicular (HPT) as well as insulin-like growth factor (IGF-1) axes can result in impaired muscle and bone strength and mobility. ${ }^{21}$
Besides these theoretical approaches, clinicians are focusing on the incorporation of a simplified frailty assessment tool, which could be effectively integrated into the routine preoperative risk evaluation. Several scales and indices are available for more complex frailty assessment for clinicians. ${ }^{22}$ The modified frailty index (mFI), ${ }^{23}$ derived from the traditional FI - using at least 10 items of FI - was applied in the majority of studies assessing vascular surgical patients. Many papers reported higher postoperative mortality among frail patients following various vascular procedures using $\mathrm{mFI}^{24-27}$ and further composite frailty instruments, for eg, Risk Analysis Index (RAI), ${ }^{28}$ Addenbrooke's Vascular Frailty Score, ${ }^{29}$ and others. ${ }^{30,31}$ Not only mortality but postoperative adverse outcomes are also more frequent in frail individuals. Major complications, ${ }^{25,27}$ longer hospital stay ${ }^{29,32}$ and non-home discharge $e^{29,33}$ following vascular surgery were associated with frailty. Higher $\mathrm{mFI}$ scores are associated with increased incidence of other postoperative complications, as acute myocardial infarction (MI), stroke, progressive renal failure and graft failure. Together with dialysis dependency, postoperative renal insufficiency, MI, postoperative acute renal failure and black race, an mFI score of 0.54 0.63 , significantly increases the risk of mortality and complications after lower extremity revascularizations. ${ }^{34}$

Even a single marker of frailty can be a good predictor of adverse outcome following vascular surgery. In a large retrospective study analysing the data of 9782 functionally dependent and independent propensity-matched patient pairs derived from the American College of Surgeons National Surgical Quality Improvement Program database, functional dependency, as a marker of advanced frailty, was associated with 1.75 -fold increased risk of death following vascular or general surgical procedures. ${ }^{35}$ Lee et al found that core muscle size is a much more significant predictor of long-term mortality following open abdominal aortic aneurysm (AAA) repair than ASA scoring in itself. ${ }^{36}$ The psoas muscle area is an independent predictor of all-cause mortality after open and endovascular AAA repairs. ${ }^{37}$ The decline of gait parameters, used alone or as a part of a complex frailty assessment, is the leading symptom of peripheral arterial disease (PAD). Despite that frailty and PAD may interfere in gait performance, gait assessment was a sensitive and specific early predictor of pre-frailty, ${ }^{38}$ and the gait initiation test can be effectively used in the evaluation of motor performance among PAD patients regardless of frailty. ${ }^{39}$ The FI for critical limb ischemia (CLI) procedures is a risk factor for postoperative morbidity and in- 
hospital mortality with a hazard ratio of 3.21 and 6.32, respectively. Moreover, the CLI Frailty Index was significantly influencing the mortality rate 2 years after amputation-free survival (AFS). This finding can improve the prognostic prediction of outcome and could help clinicians in the selection of firstly applying treatment strategy. ${ }^{40}$ Examining gender differences in a propensity scorematched analysis after lower limb endovascular interventions and a 1-year follow-up period, the following results were reported: women were at lower risk of mortality than men, despite that they underwent significantly more repeated revascularization procedures. ${ }^{41}$ Frailty and self-efficacy are independent predictors for postoperative 6 mins walking-distance (6MWD) after elective open AAA surgery, which means that not only physical status, but also psychological factors can predict the effectiveness of postoperative rehabilitation and outcome. This suggests that attempts to improve self-efficacy preoperatively could improve rehabilitation after AAA surgery. ${ }^{42}$ When adjusted for comorbidity and surgery type, frailty seems to impact medium-term survival (within 2 years) in vascular patients and the first clinical impressions in this patient cohort is an independent predictor of all-cause mortality and long-term postoperative death. This would help clinicians in a more precise definition of high-risk vascular surgery. ${ }^{43}$

Frailty was also made responsible for longer in-hospital stays and an increased rate of non-home discharge. The need for a higher level of care or nursing facility after hospitalization occurred with a higher incidence compared to non-frail patients. ${ }^{44,45}$

We have found one systematic review questioning the association between frailty and poorer postoperative outcome. The study focused on patients older than 75 years and reported several types of intervention, both acute and elective, including vascular surgeries. ${ }^{46}$ The review presented 23 studies focusing mostly on the relationship between frailty and short-, and long-term mortality, postoperative complications and length of stay. Though they have found publications reporting non-significant results in some aspects, in all of the researches, frailty have been consistently related to adverse outcomes. In addition, the above-mentioned review, beyond excluding studies using single markers to determine frailty, was limited by including a very heterogeneous surgical patient population. ${ }^{46}$

Reports with the largest patient population and the clearest results about the effects of frailty in the field of vascular surgery are listed in Table 1.

\section{Frailty Index}

A simplified frailty index is easily obtainable from patient general characteristics. The index counts deficits in health available in standard clinical data. The fraction of deficits that are present and those which are not gives us the exact index. Numerous calculation procedures have been created, but usually, the standard cut-off points are set at levels 0 (excellent health condition); 0.25 (very good); 0.5 (good); 0.75 (poor or fair) and 1 (very poor). ${ }^{47}$ Understanding why and how frailty is influencing the postoperative outcome is not easy. Intentions to modify frailty risk factors are not yet entirely integrated into the daily routine. The increase of frailty index (FI) level causes a rise in the occurrence of postoperative wound infections and the odds ratio for mortality in vascular patients. ${ }^{26,48,49}$ Complications and death also showed a higher incidence in female frail patients, especially following infrainguinal vascular surgery. ${ }^{27,29}$ Patients older than 60 , with a recognized risk of frailty and functional or cognitive impairment, are predicted to a longer hospital stay and to poorer outcome. ${ }^{32}$ Therefore, it is necessary to identify and possibly modify the frailty index of these patients. Unfortunately, we did not find studies examining the influence of preoperative therapeutic interventions applied in order to reduce frailty symptoms.

\section{Modifiable Factors}

Our research showed that several elements of frailty seem to be modifiable risk factors, where therapeutic interventions are available and can be applied by involving professionals and experts (psychologist, psychiatrist, social workers, etc.). These interventions might effectively reduce the vulnerability of patients, keeping in mind that the short- or long-term negative outcomes are not negligible. Modifiable factors have several effects on short-, midand long-term outcomes. Short-term outcomes, as 30-day mortality, 30-days hospital readmission rate, postoperative major cardiac events, ischaemic complications, new onset arrhythmias, need for inotropic support and heart failure, pulmonary complications (severe pneumonia, need for mechanical ventilation longer than $48 \mathrm{hrs}$, unplanned tracheal re-intubation or occurrence of pulmonary embolism) and surgical site infections can be influenced by a 4-6 weeks of preoperative cardiopulmonary exercise training. Mid-term outcomes, like rehabilitation times, graft failure or limb amputation incidences, are dependent on preoperative glycaemic statuses, smoking behaviours and protein 
Table I Publications Reporting The Effects Of Frailty On Patients Undergoing Vascular Procedures

\begin{tabular}{|c|c|c|c|}
\hline Reference & Study Population & Measure Of Frailty & Results \\
\hline $\begin{array}{l}\text { Jeon-Slaughter H. et al } \\
(2017)^{41}\end{array}$ & $\begin{array}{l}\text { I084 patients' propensity matched data who } \\
\text { underwent I } 702 \text { endovascular procedures } \\
\text { ( } 449 \text { men and } 449 \text { women). }\end{array}$ & Frailty hazard ratios & $\begin{array}{l}\text { Women are at a lower risk of mortality than } \\
\text { men; however, they underwent significantly } \\
\text { more frequent repeat } 12 \text {-month } \\
\text { revascularization procedures. }\end{array}$ \\
\hline $\begin{array}{l}\text { Morisaki K. et al } \\
(2017)^{40}\end{array}$ & $\begin{array}{l}\text { Retrospective, } 266 \text { patients undergoing } \\
\text { infrapopliteal revascularization. Primary end- } \\
\text { point: 2-year amputation-free survival (AFS). }\end{array}$ & $\begin{array}{l}\text { CLI Frailty Index } \\
\text { compared with } \mathrm{mFI}\end{array}$ & $\begin{array}{l}\text { The CLI Frailty Index is a risk factor for } 2 \text { - } \\
\text { year AFS after revascularization. }\end{array}$ \\
\hline $\begin{array}{l}\text { Ali TZ et al }(2017) \\
\text { revascularizations }{ }^{34}\end{array}$ & $\begin{array}{l}\text { Retrospective, } 4704 \text { patients ( } 64 \% \text { men and } \\
36 \% \text { women) undergoing infrainguinal arterial } \\
\text { bypass surgery. }\end{array}$ & $\mathrm{mFI}$ & $\begin{array}{l}\text { Patients with } \mathrm{mFl} \text { score of } 0.54-0.63 \text { were at } \\
\text { significantly higher risk of mortality and } \\
\text { postoperative complications, beside black } \\
\text { race, dialysis dependency, renal insufficiency, } \\
\mathrm{MI} \text { and acute renal failure. }\end{array}$ \\
\hline Hayashi K. et al $(2017)^{42}$ & 70 patients undergoing open AAA surgery. & $\begin{array}{l}\text { HADS-A, 6MWD, } \\
\text { SEPA }\end{array}$ & $\begin{array}{l}\text { Preoperative self-efficacy predicted } \\
\text { postoperative } 6 \mathrm{MWD} \text { after AAA surgery, } \\
\text { which could predict and improve the } \\
\text { effectiveness of postoperative rehabilitation. }\end{array}$ \\
\hline $\begin{array}{l}\text { O'Neill B.R. et al } \\
(2016)^{43}\end{array}$ & $\begin{array}{l}\text { Retrospective review and follow-up of } 392 \\
\text { patients (Male/Female } 317 / 75 \text { ) undergoing } \\
\text { vascular surgery. }\end{array}$ & Complex, unspecified & $\begin{array}{l}\text { The hazard ratio for mortality for frail vs } \\
\text { not-frail was } 2.14 \text { ( } 95 \% \mathrm{Cl} \text { I.5I-3.05). The } \\
\text { time to } 20 \% \text { mortality: } 16 \text { months in the frail } \\
\text { group; } 33 \text { months in the not-frail group. }\end{array}$ \\
\hline Drudi et al $(2016)^{37}$ & $\begin{array}{l}\text { Retrospective, } 149 \text { patients ( } 84 \% \text { male, } 16 \% \\
\text { female) undergoing endovascular or open } \\
\text { AAA repair. }\end{array}$ & $\begin{array}{l}\text { Psoas muscle area at } \\
\text { L4 }\end{array}$ & $\begin{array}{l}\text { In a Cox-regression analysis adjusted for age, } \\
\text { sex, revised cardiac risk index and surgical } \\
\text { approach), PMA showed significant } \\
\text { association with postoperative all-cause } \\
\text { mortality (mean follow-up: } 22.4 \text { months). }\end{array}$ \\
\hline Ehlert et al $(2016)^{25}$ & $\begin{array}{l}\text { Retrospective, data derived from ACS } \\
\text { NSQIP, 72, I06 patients (approximately 70\% } \\
\text { male in the differently examined groups) } \\
\text { undergoing carotid revascularization, AAA } \\
\text { repair and lower extremity revascularization } \\
\text { for PAD. }\end{array}$ & $\mathrm{mFI}$ & $\begin{array}{l}\text { mFI showed better discrimination regarding } \\
\text { mortality than LCRI and ASA. Regarding } \\
\text { class IV complications, similar findings were } \\
\text { reported after OAR and EVAR. There were } \\
\text { no significant differences in the } \\
\text { discrimination of mortality in the } \\
\text { endovascular cohort or major complications } \\
\text { after open or endovascular PAD or carotid } \\
\text { endarterectomy. }\end{array}$ \\
\hline Srinivasan et al $(2016)^{30}$ & $\begin{array}{l}\text { Retrospective, single centre, I } 84 \text { patients } \\
(85 \% \text { male) treated for rAAA ( } 108 \\
\text { underwent an open repair). }\end{array}$ & Complex, unspecified & $\begin{array}{l}\text { A multivariate logistic regression model I2- } \\
\text { month mortality using Katz score, Charlson } \\
\text { score, number of admission medicines, visual } \\
\text { and hearing impairment, haemoglobin level, } \\
\text { and statin use as predictors reached an AUC } \\
\text { of } 0.84 \text {. }\end{array}$ \\
\hline $\begin{array}{l}\operatorname{van} \text { Netten JJ et al } \\
(2016)^{49}\end{array}$ & $\begin{array}{l}\text { Retrospective, data derived from ACS } \\
\text { NSQIP, } 9244 \text { patients underwent above- or } \\
\text { below-knee amputation. }\end{array}$ & Complex, unspecified & $\begin{array}{l}\text { An additive risk index of II components (age, } \\
\text { congestive heart failure, COPD, steroid use, } \\
\text { major cardiac surgery, functional dependency, } \\
\text { dyspnea, dialysis, impaired sensorium, } \\
\text { preoperative sepsis) for } 30 \text {-day mortality had } \\
\text { a c-index of } 0.74 \text {, clinical intervention should } \\
\text { be taken over a score of } 5 \text {. }\end{array}$ \\
\hline
\end{tabular}

(Continued) 
Table I (Continued).

\begin{tabular}{|c|c|c|c|}
\hline Reference & Study Population & Measure Of Frailty & Results \\
\hline Arya et al $(2016)^{33}$ & $\begin{array}{l}\text { Retrospective, data derived from ACS } \\
\text { NSQIP, I5,843 home-dwelling patients } \\
\text { underwent elective vascular surgery. }\end{array}$ & $\mathrm{mFI}$ & $\begin{array}{l}\text { Frailty significantly increased the risk of non- } \\
\text { home discharge even in presence or absence } \\
\text { of complications. }\end{array}$ \\
\hline $\begin{array}{l}\text { Scarborough et al } \\
(2015)^{35}\end{array}$ & $\begin{array}{l}\text { Retrospective, data derived from ACS } \\
\text { NSQIP, patients undergoing complex general } \\
\text { or vascular operation } 9782 \text { functionally } \\
\text { dependent ( } 51 \% \text { female) and independent } \\
\text { ( } 72 \% \text { female) propensity-matched patient } \\
\text { pairs. }\end{array}$ & $\begin{array}{l}\text { Dependence in } \\
\text { activities of daily living }\end{array}$ & $\begin{array}{l}\text { Dependent patients faced with significantly } \\
\text { increased risk of } 30 \text {-day postoperative } \\
\text { mortality, major morbidity, failure to rescue } \\
\text { and reoperation-procedure-specific analyses } \\
\text { showed similar results regarding mortality } \\
\text { and morbidity following endovascular and } \\
\text { open AAA repair, carotid endarterectomy, } \\
\text { infrainguinal bypass graft surgery. }\end{array}$ \\
\hline Arya et al $(2015)^{24}$ & $\begin{array}{l}\text { Retrospective, data derived from ACS } \\
\text { NSQIP, 23,207 patients (approximately } 70 \% \\
\text { female in each group) undergoing } \\
\text { endovascular or open AAA repair. }\end{array}$ & $\mathrm{mFI}$ & $\begin{array}{l}\text { Frailty was independently associated with } 30 \text { - } \\
\text { day postoperative mortality, morbidity and } \\
\text { failure to rescue rate after EVAR and OAR. }\end{array}$ \\
\hline $\begin{array}{l}\text { Brahmbhatt et al } \\
(2015)^{27}\end{array}$ & $\begin{array}{l}\text { Retrospective, data derived from ACS } \\
\text { NSQIP, } 24,645 \text { patients undergoing } \\
\text { infrainguinal vascular surgery. The analysis } \\
\text { focused on the variation of } \mathrm{mFI} \text { scores across } \\
\text { gender differences. }\end{array}$ & $\mathrm{mFI}$ & $\begin{array}{l}\text { Women were frailer. Female gender and } \\
\text { higher } \mathrm{mFl} \text { showed significant association } \\
\text { with } 30 \text {-day postoperative mortality and } \\
\text { major morbidity. The interaction of frailty } \\
\text { and female gender showed the highest } \\
\text { impact on adjusted } 30 \text { day postoperative } \\
\text { mortality and morbidity. }\end{array}$ \\
\hline Melin et al $(2015)^{28}$ & $\begin{array}{l}\text { Retrospective, data derived from ACS } \\
\text { NSQIP, } 44,832 \text { patients undergoing carotid } \\
\text { endarterectomy. }\end{array}$ & Frailty RAI & $\begin{array}{l}\text { Frailty RAI, as continuous variable, showed } \\
\text { significant association with mortality, stroke, } \\
\text { MI and LOS. High-risk patients (RAI }>10 \text { ) } \\
\text { faced with increased risk of stroke and death. }\end{array}$ \\
\hline Ambler et al $(2015)^{29}$ & $\begin{array}{l}\text { Prospective, single centre, } 4 \mathrm{I} 3 \text { patients aged } \\
\text { over } 65 \text { years with a LOS }>2 \text { days admitted } \\
\text { to a tertiary vascular unit. }\end{array}$ & AVFS & $\begin{array}{l}\text { AVFS was good predictor of } 12 \text { months } \\
\text { postoperative mortality, prolonged LOS, } \\
\text { discharge to care institutions, and showed } \\
\text { significant association with readmission rates. }\end{array}$ \\
\hline Partridge et al $(2015)^{32}$ & $\begin{array}{l}\text { Prospective, observational, } 125 \text { patients } \\
\text { ( } 68.8 \% \text { male), aged over } 60 \text { years, undergoing } \\
\text { elective and emergency arterial vascular } \\
\text { procedures. }\end{array}$ & $\begin{array}{l}\text { EFS, functional status } \\
\text { and MoCA }\end{array}$ & $\begin{array}{l}\text { EFS } \geq 6.5 \text { was predictive for extended LOS } \\
\text { ( } 12 \text { days or above) (c-index } 0.66 \text { ). With the } \\
\text { addition of MoCA }<24 \text { to the model, c-index } \\
\text { reached } 0.70 \text { ). }\end{array}$ \\
\hline
\end{tabular}

Abbreviations: AAA, abdominal aortic aneurism; ACS NSQIP, American College of Surgeons National Surgical Quality Improvement Program; AUC, area under curve; ASA, American Society of Anesthesiologists; AVFS, Addenbrooke's Vascular Frailty Score; CLI, Critical Limb Ischaemia; COPD, chronic obstructive pulmonary disease; EFS, Edmonton Frailty Scale; EVAR, endovascular aneurysm repair; LCRI, Lee Cardiac Risk Index; LGNRI, Low Geriatric Nutritional Risk Index; LOS, length of hospital stay; mFI, modified Frailty Index; MI, myocardial infarction; MoCA, Montreal Cognitive Assessment; OAR, open aneurysm repair; PAD, peripheral artery disease; PMA, psoas muscle area; rAAA, ruptured abdominal aortic aneurism; RAI, Risk Analysis Index; RVU, relative value units.

levels. Long-term complications as 3-year survival can be effectively improved by exercise training and modification of smoking behaviours. These preoperative interventions are detailed in the relevant sections of this review.

Randomized trials exist for potential therapeutic strategies, such as physical exercising, ${ }^{50,51}$ nutritional preparation ${ }^{52}$ or psychological intervention. The Frailty Intervention Trial ${ }^{53}$ examined the effect of a multidisciplinary interventional method compared to the usual care of frail patients in a randomized controlled patient population. The study, however, reported data of hospitalization of any cause and not data of patients undergoing surgical procedures.

Unfortunately, we have found only a few publications reporting data on frail patients who underwent any therapeutic intervention preoperatively, even if the individual was diagnosed with frailty syndrome or mild cognitive 
impairment due to natural aging, dementia of any cause or due to organic dysfunction. The aim of the applied interventions in order to reduce frailty index could decrease the adverse outcomes in patients whose vulnerability or frailty syndrome seems to be irreversible. Successful therapies have positive effects not only on elderly patients themselves but also on their families and the whole society. ${ }^{54}$

\section{Discussion}

This review highlights some significant key points about the effects of frailty on the postoperative outcome after vascular surgeries. Based on the findings, it is clear that preoperative risk stratification should include simultaneous functional and psychosocial screening. The use of frailty evaluation systems could be a good predictor for postoperative adverse outcome in vascular surgery. Frailty increases the sensitivity of the clinically applied physiological scoring scales, like the V-POSSUM system. A multidisciplinary approach would be required to identify patients at high risk and start their preconditioning in order to improve the short-, mid- and long-term outcomes. It is well accepted that during preoperative management of vascular patients, we have to face some limitations. With this in mind, our review aims to highlight the possibilities of preoperative interventions in a larger view. The implementation of the different prehabilitation strategies varies institutionally and it is strongly dependent on technical supplies and human resources.

\section{Cardiopulmonary Exercise Testing (CPET) In Vascular Disease}

Cardiopulmonary exercise testing (CPET) is a standard method in the preoperative assessment of patients undergoing major surgery. It includes the measurement of the anaerobic threshold (AT); the maximum oxygen consumption (VO2 peak); the total time on the Duke Treadmill test and the ventilator equivalents for oxygen and carbon dioxide consumption (VE/VO2 and VE/VCO2, respectively). ${ }^{55}$ The peak of VO2 stands for the maximum rate of oxygen consumption measured during incremental exercise ${ }^{56}$ and it can be expressed by the ratio of ventilatory equivalent and carbon dioxide consumption (VE/VCO2). The peak of $\mathrm{VO} 2$ is an important marker for cardiovascular disease; however, it is often underused in clinical practice. ${ }^{57}$

According to the actual literature, the Duke treadmill score has a very good prognostic value in examining physical performance. Studies state that imaging is not even required if the patient reaches a value, superior to 10 metabolic equivalents (MET) on physical examination and there is no reason for stress testing before noncardiac surgeries in those patients who achieve 4 METs without symptoms. ${ }^{58}$ However, there are findings reporting that an objective exercise testing between 4 and 6 METs is associated with low cardiovascular risk ${ }^{59}$ and the measurement of mixed venous oxygen tension (PVO2) might only be used during the identification of patients at risk of developing postoperative complications. Parameters of the treadmill should not be used separately and without clinical assessment tools. ${ }^{60}$

Cardiorespiratory fitness testing in patients with diagnosed abdominal aortic aneurism (AAA) may be problematic, but should not be automatically excluded from the preoperative screening tools. Randomized trials showed that supervised exercise testing in patients scheduled for AAA repair can also be improving and could effectively direct the clinical decision-making process regarding the type of operation or the postoperative allocation. ${ }^{55,61,62}$ During exercise testing of AAA patients, a moderately higher rate of blood pressure fluctuation was observed compared to age-matched controls and no serious event occurred during the examination. ${ }^{63}$ The research group stated that CPET can be safely and routinely used during the preoperative risk stratification process. ${ }^{63}$ It is potentially useful in AAA patients in the prediction of postoperative complications and the length of critical care and hospital stay. ${ }^{61}$ The test is also declared to be an independent predictor of a 30-day outcome, 30-day mortality and 3-year survival. ${ }^{62,64}$ Some evaluations did not reach the same conclusion: $\mathrm{CPE}$ testing combined with a simple co-morbidity screening showed reduced mid-term survival in patients undergoing successful AAA repair ${ }^{63}$ and test results were associated neither with 30-day mortality nor with the length of the hospital stay. ${ }^{65}$ These latter publications, however, are in accordance regarding the prediction of postoperative complications like cardiac events (myocardial infarction, ischemic complications, new onset arrhythmia, need for inotropic support for at least $12 \mathrm{hrs,} \mathrm{congestive} \mathrm{heart} \mathrm{failure)} \mathrm{or} \mathrm{pulmonary} \mathrm{com-}$ plications (pneumonia, need for mechanical ventilation longer than $48 \mathrm{hrs}$, unplanned tracheal re-intubation, pulmonary embolism) ${ }^{63,65}$ In certain centres, CPET is routinely used in the decision-making process regarding the type of the operation (endovascular or open repair surgery); however, retrospective data confirm that the utilization of preoperative CPET is useful mostly in the 
prediction of complications and the reduction of health care utilization. ${ }^{58}$ It seems that CPET can help in the differentiation of the existing pathology, no matter if it is cardiovascular or respiratory. ${ }^{62}$

Based on examinations, the American College of Cardiology/American Heart Association (ACC/AHA) guidelines concluded that the routine use of CPET in noncardiac interventions, including vascular surgery patients, may be more beneficial than its risks (evidence level B, IIb). ${ }^{66}$ Modalities for stress testing are different; therefore, we have to minimize the risks of the examination itself. Exercise electrocardiography is a widely available tool for testing. However, in vascular patients, its usage is limited: patients suffering from claudication, limb ischemia, peripheral vascular diseases and poor functional capacity are unable to reach ischemic thresholds. In addition, this testing type provides few information about cardiac function examinable with other imaging modalities, like echocardiography, myocardium scintigraphy or cardiac magnetic resonance imaging (MRI). ${ }^{67}$ Stress echocardiography may be preferred in patients awaiting for carotid endarterectomies, peripheral vascular interventions or patients with known bronchospastic lung diseases. Additional information about cardiac functions are provided; however, because of dobutamine usage, this type of testing should be avoided in patients with known arrhythmias and symptomatic or large aortic aneurysms (55 millimeters or larger). ${ }^{66,68}$ Myocardial perfusion imaging is an effective alternative of the above-mentioned modalities for testing intermediate or high-risk vascular patients. It is the most suitable for patients with known left or right ventricular dysfunction and it is designed to identify flow-limiting stenosis. It should be avoided in patients with known lung disease, as dipyridamole can induce bronchospasm; and in severe carotid stenosis because of its hypotensive effect. Long testing times, ionizing radiation and technetium usage with a very low hepatic clearance represent the most severe disadvantages of this technique. ${ }^{67,69}$ In addition, this imaging form reveals ischaemia only in the most unsupplied myocardial territories and it cannot detect subclinical atherosclerosis.

The above-described findings give facility to clinicians in the routine use of CPE testing in vascular surgery patients. Where clinical doubt exists regarding a candidate's suitability or the postoperative outcomes, exercise testing can be safely applied if the modality for testing is well chosen.

\section{Nutrition}

Outcomes associated with malnutrition in vascular surgery candidates are still unclear. Patients awaiting vascular surgery are frequently in poor nutritional condition, consisting as part of the frailty-syndrome. Malnutrition is associated with a longer hospital stay, muscle weakness, fatigue, depression, immunological dysfunction, slower wound healing and longer need for rehabilitation. ${ }^{70,71}$ In vascular patients, serious wound infection could lead to the contamination of the vascular graft, causing severe bleeding, loss of the limb or even death. ${ }^{72}$ It is known that a 10-day preoperative nutritional supplementation, with physiotherapy and cognitive training in frail patients undergoing abdominal interventions, significantly reduces the length of postoperative hospital stay and the need for prolonged rehabilitation. ${ }^{73}$

Even postoperative morbidity and mortality can be significantly reduced by the use of any form (enteral or parenteral) of preoperative alimentation, especially by improving the immune competence of the patient. ${ }^{72,74}$ It is also well accepted that metabolic complications can be effectively reduced by the preference of an early started enteral nutrition instead of parenteral. The avoidance of nasogastric tube is recommended in order to the fast return of normal bowel function and the reduction of pulmonary complications. ${ }^{75} \mathrm{In}$ case of bowel dysfunction, metoclopramide and erythromycin have to be chosen as a first-line therapy. ${ }^{75}$

After lower extremity bypass surgeries, a higher morbidity and mortality was observed in patients with preoperative hypalbuminemia. ${ }^{76}$ This finding was confirmed also in candidates for juxtarenal and thoracoabdominal aortic aneurysm repairs, independently of the type of the surgery (open vs. endovascular abdominal aortic aneurysm repair). ${ }^{76,77}$ Patients with severe hypalbuminemia (albumin levels lower than $2.4 \mathrm{~g} / \mathrm{dl}$ ) have increased 30-day mortality, which can be reduced by a controlled preoperative nutritional intake. ${ }^{76,78}$ Based on findings, a guiding list was created to help the preoperative clinical assessment of vascular patients. In this population, the preoperative mechanical bowel preparation should be ignored; early removal or avoidance of nasogastric tube is preferred; metoclopramide and erythromycin have to be chosen as first-line prokinetics; enteral feeding can be started in the first 24-48 hrs postoperatively and glucose levels should not exceed $11.9 \mathrm{mmol} / \mathrm{L}(215 \mathrm{mg} / \mathrm{dl}){ }^{79}$ In order to avoid dehydration, consequent pain and nausea, preoperative fasting is not recommended. Clear carbohydrate fluids applied before 
the operation (at least two hours before) can decrease postoperative stress levels and anxiety. ${ }^{80}$ Oral protein supplementation and short-term continuous supervised physical exercise training (six weeks at least) are the most improving interventions in frail patients undergoing surgery. ${ }^{81}$ In candidates for elective AAA repair surgery, the physical training significantly with protein supplementation reduces postoperative cardiorespiratory events, renal complications and the length of hospital stay. ${ }^{82}$ Equal results were reported after a 4-week long preoperative high-intensity (HIT) interval training in AAA repair awaiting patients. ${ }^{83}$

\section{Smoking}

The most common modifiable risk factor in patients with vascular disease is smoking. The level of nicotine dependence can be easily specified by the Fagerstrom test. ${ }^{84}$ In addition to the well-known physiological risk factors (congestive heart failure, age, diabetes, chronic obstructive pulmonary disease, unused statin therapy, chronic renal failure), smoking is also independently associated with an increased risk of mortality following carotid endarterectomies. ${ }^{85}$ After lower extremity bypasses, 30-days hospital readmission rate was increased by current smoking; besides dialysis-dependence, tissue loss, graft insufficiency and female gender. Consequently, the number of readmissions are linearly associated with long-term limb loss. ${ }^{86}$ However, there are findings describing that the presence of smoking, metabolic syndrome or renal insufficiency are less important in risk prediction of postoperative infectious complications, compared to operating times, presence of preoperative open wound or inpatient operation. ${ }^{87}$

Even if smoking rates have decreased, ${ }^{88}$ few of the vascular surgeons give assistance to their patients in the cessation procedure, even if patients themselves have the intention to quit, independently of the planned operation or the symptomatic status. ${ }^{88}$ Those who have a history of more than 30 pack-year have more failed attempts to quit in their lives compared to episodic smokers or those who have a shorter pack-year history. A brief smoking cessation (3 months) with the help of vascular surgeon can increase patients' desire to quit. It is also important to make patients aware of the possible long-term consequences of nicotine dependence. ${ }^{89}$ The VAPOR trial (Vascular Physician Offer and Report) designed a threestep smoking cessation intervention (advising to quit, replacing nicotine, telephone-followed quitline) and compared it to routine care. The trial reported a $40.3 \%$ 3 -month cessation in the intervention group (23 patients of 57) after the physician's advice and the nicotine replacement therapy. $^{90}$

Our review finding suggests that an exact preoperative screening regarding smoking behaviours of the patients and the intention to intervene is an effective way to reduce postoperative infectious complications and future hospital readmissions.

\section{Management Of Glycemic Status}

The relationship between high blood glucose levels and worsened postoperative outcomes (major amputation, graft occlusion, tissue loss, cardiovascular events, renal insufficiency) is well known. Poor glycaemic control is associated with an enforced progression of cardiovascular disease, an increased mortality and an elevated perioperative complication rate. ${ }^{91}$ Mortality rate is doubled when glucose levels are above $140-150 \mathrm{mg} / \mathrm{dl}$ in the perioperative period. The goal of insulin therapy is to avoid surgical wound complications, ${ }^{92}$ gastrointestinal function and inflammatory responses. ${ }^{70}$ Every $40 \mathrm{mg} / \mathrm{dl}$ increase in glucose levels increases the risk for graft failure and infection by $30 \%$, followed by a longer intensive care unit (ICU) stay. ${ }^{93}$ Increased glucose tolerance, diagnosed by fasting glucose levels and OGTT (oral glucose tolerance test) resulted in a significantly higher risk for developing postoperative cardiovascular events (myocardial infarction, angina pectoris, transient ischemic attacks or cerebrovascular occlusions), compared to diabetic patients, showing non-significant risk-increase. ${ }^{94}$

After lower extremity revascularization, elevated haemoglobin $\mathrm{A} 1 \mathrm{c}(\mathrm{HbA1c})$ levels are associated with increased risk for limb amputation and major adverse limb events. This tendency was also observed in patients having $\mathrm{HbA} 1 \mathrm{c}$ levels higher than $7 \%$, with no preoperative diagnosis of diabetes mellitus. These latter patients are at 50\% higher risk for amputation or major adverse events than patients with normal glycolysed haemoglobin levels. ${ }^{95,96}$ Even a short-term thigh glycaemic control has the potential to reduce amputation rates in patients with type 2 diabetes ${ }^{97}$ and the risk for surgical site infections. ${ }^{98} \mathrm{HbAlc}$ can identify patients at higher long-term mortality risk before PAD revascularization, even if candidates have an unknown glycaemic status or undiagnosed diabetes mellitus. ${ }^{99}$ The ADVANCE trial (Action in Diabetes and Vascular Disease: Preterax and Diamicron Modified Release Controlled Evaluation) reported comparison of the risk prediction values of haemoglobin glycation index (HGI) and HbAlc levels. According to the trial, in patients with type 2 diabetes, the risk 
evaluating the value of either HbAlc and HGI cannot be clearly suggested, due to the discordant results. ${ }^{100}$ It has also been shown that diabetic and non-diabetic patients with longterm elevated blood glucose levels are at an increased risk for abdominal aneurysm progression. During a 5-year ultrasound guided follow-up (subtrial of Viborg Vascular Randomized Screening Trail), ${ }^{101}$ abdominal aortic aneurysms under 5 centimetres of diameter have shown significant progress in patients with higher HbAlc levels, compared to euglycaemic individuals. ${ }^{101}$

It is suitable for non-diabetic patients undergoing vascular surgery to be tested for glucose regulation dysfunctions before interventions. It seems that gylcolysed haemoglobin is a useful tool to predict the risk for infections, long-term risk for limbloss and postoperative mortality.

\section{Early Rehabilitation}

In general surgery patients, fast-track recovery programs have been created, resulting in decreased patient morbidity and mortality after major surgeries. ${ }^{102}$ Such programs have not been created specifically for vascular surgery patients; however, the protocols available can be adapted to this patient population as well. The most commonly used multimodal evidence-based fast-track program is described by the ERAS protocol (Enhanced Recovery After Surgery), which, besides the preoperative interventions, involves all the major postoperative principles. ${ }^{79}$ The program is already standard in colorectal and general abdominal surgery. The major principles are: reduction in the use of nasogastric tubes and enforcement of early enteral nutrition; early removal of drains; use of patient-controlled and non-opioid analgesia; goal-directed fluid therapy; avoidance of urine catheters when possible and early mobilization. ${ }^{79}$ An important element of early recovery is pain management. Patient-controlled epidural analgesia resulted in fewer cardiovascular and renal complications in the postoperative period, compared to systemic opioid usage, with no difference in mortality rates. ${ }^{103}$

The ERAS was used by randomized prospective and other studies, ${ }^{62,102-104}$ involving vascular surgery candidates. After elective open infrarenal aneurysm repair surgery, patients managed with a fast-track recovery program (avoidance of longterm preoperative fasting and bowel preparation, early postoperative enteral nutrition, patient-controlled epidural analgesia (PCEA) early mobilization) showed significantly better outcomes compared to those receiving conservative treatments. ${ }^{102}$ The need for postoperative-assisted ventilation, the incidence of all-cause complications and the time to reach full enteral nutrition were significantly decreased. ${ }^{102}$

Deriving from its multifactorial characteristic, this clinical syndrome needs multimodal intervention: physical exercising, maintenance of muscle strength, adequate perioperative nutrition, glycaemic control and management of smoking behaviours can lead to increased patient survival and a quality of life even in advanced ages. With exercise prehabilitation programs, the health-related quality-of-life of vascular surgery patients seems to be significantly improved after discharge. ${ }^{105}$ The preoperative management algorithm of frail vascular surgery patients is presented in Figure 2.

\section{Limitations}

During data research, we had to face some limitations. Comorbidities may vary by races and nationalities, while frailty as a well-defined syndrome lacks these discrepancies. Our review did not differentiate vascular procedure types (except varicectomies) and operations were considered more or less equivalent to each other. This makes the generalizability of our findings questionable. We also have no data about the ease of implementation of prehabilitation procedures, as it varies centre by centre and it is dependent on the human and financial resources of each institution. Therefore, the cost-effectiveness of the interventions in the field of vascular frail patients is very specific. Additionally, our review lacks detailed data about the quality of life of the patients after discharge, which could also be an important reflection to the effectiveness of prehabilitation programs applied in order to reduce negative influence of frailty syndrome on the outcome. Publication found in this latter field reports that the generalizability of the data is limited by the heterogeneity of the patient populations; thus, the creation of a statistical pool across trials was not possible. ${ }^{105}$ Further evaluations are needed. Regarding cost-effectiveness and resource utilisation, we lack data in the field of vascular surgery frail patients, despite that several analyses are available in other surgery types. These studies reported increased post-operative resource utilisation across various metrics, but the improved cost-effectiveness seemed to be of low certainty due to the inconsistency among researches. ${ }^{106,107}$

\section{Conclusion}

Frailty has a great influence on postoperative outcomes in patients undergoing vascular surgery. The development of well-designed prehabilitation programs would 


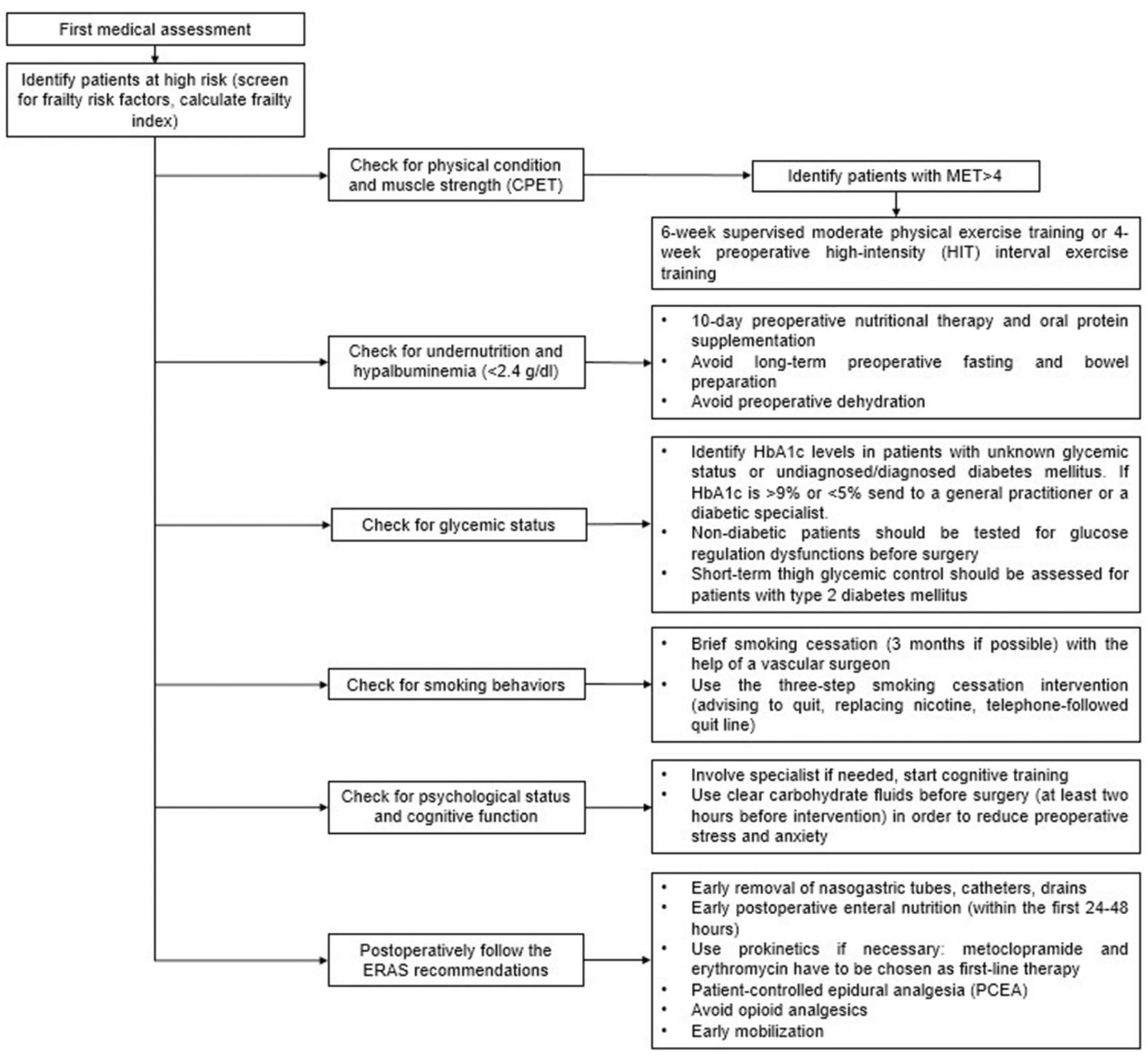

Figure 2 Preoperative screening and intervening algorithm of frail vascular patients.

help the achievement of a better outcome in this patient population. It is well accepted that surgery itself can cause postoperative frailty. It is desirable to understand prevention methods, because frailty syndrome can also occur as a consequence of complex and stressful vascular surgeries. Efforts are needed in order to reduce the length of stay, the number of readmissions and the time required for recovery. We have to understand that frailty is a dynamically changing state of the patient: pre-frail patients, with the worsening of their conditions, can anticipate in a complex and irreversible frailty-syndrome, but with goal-directed preoperative interventions, this deterioration can be prevented.

\section{Disclosure}

This research did not receive any specific grant from funding agencies in the public, commercial or not-for-profit sectors. AS reports being on a speaker bureau for GE Healthcare (for pediatric hemodynamic monitoring) and receiving a fee from Amomed for consultation about vazopressin. The authors report no other conflicts of interest in this work.

\section{References}

1. Sankar A, Johnson SR, Beattie WS, Tait G, Wijeysundera DN. Reliability of the American Society of Anesthesiologists physical status scale in clinical practice. Br J Anaesth. 2014;113(3):424-432. doi:10.1093/bja/aeu100 
2. Copeland GP, Jones D, Walters M. POSSUM: a scoring system for surgical audit. $B r \quad J$ Surg. 1991;78(3):355-360. doi:10.1002/ bjs. 1800780327

3. Prytherch DR, Sutton GL, Boyle JR. Portsmouth POSSUM models for abdominal aortic aneurysm surgery. Br J Surg. 2001;88(7):958963. doi:10.1046/j.0007-1323.2001.01820.x

4. Elias AC, Matsuo T, Grion CM, Cardoso LT, Verri PH. [POSSUM scoring system for predicting mortality in surgical patients]. Rev Esc Enferm USP. 2009;43(1):23-29. doi:10.1590/s008062342009000100003

5. Prytherch DR, Ridler BM, Beard JD, Earnshaw JJ. A model for national outcome audit in vascular surgery. Eur $J$ Vasc Endovasc Surg. 2001;21(6):477-483. doi:10.1053/ejvs.2001.1369

6. Xue QL, Fried LP, Glass TA, Laffan A, Chaves PH. Life-space constriction, development of frailty, and the competing risk of mortality: the Women's Health And Aging Study I. Am J Epidemiol. 2008;167(2):240-248. doi:10.1093/aje/kwm270

7. Regier DA, Kuhl EA, Kupfer DJ. The DSM-5: classification and criteria changes. World Psychiatry. 2013;12(2):92-98. doi:10.1002/ wps. 20050

8. Ellis G, Whitehead MA, Robinson D, O'Neill D, Langhorne P. Comprehensive geriatric assessment for older adults admitted to hospital: meta-analysis of randomised controlled trials. BMJ. 2011;343:d6553-d6553. doi:10.1136/bmj.d6553

9. Fairhall N, Langron C, Sherrington C, et al. Treating frailty - a practical guide. BMC Med. 2011;9:83. doi:10.1186/1741-7015-9-83

10. Strojnik V, Gabrovec B. Management of frailty at individual level: narrative review of physical activity from the European perspective of joint action on frailty - JA advantage. Zdr Varst. 2019;58(2):84 90. doi:10.2478/sjph-2019-0011

11. Kristensen SD, Knuuti J, Saraste A, et al. 2014 ESC/ESA guidelines on non-cardiac surgery: cardiovascular assessment and management: the joint task force on non-cardiac surgery: cardiovascular assessment and management of the European Society of Cardiology (ESC) and the European Society of Anaesthesiology (ESA). Eur Heart J. 2014;35(35):2383-2431. doi:10.1093/eurheartj/ehu282

12. Partridge JS, Harari D, Dhesi JK. Frailty in the older surgical patient: a review. Age Ageing. 2012;41(2):142-147. doi:10.1093/ ageing/afr182

13. Wang J, Zou Y, Zhao J, et al. The impact of frailty on outcomes of elderly patients after major vascular surgery: a systematic review and meta-analysis. Eur J Vasc Endovasc Surg. 2018;56(4):591-602. doi:10.1016/j.ejvs.2018.07.012

14. Vaupel JW, Manton KG, Stallard E. The impact of heterogeneity in individual frailty on the dynamics of mortality. Demography. 1979;16(3):439-454.

15. Makary MA, Segev DL, Pronovost PJ, et al. Frailty as a predictor of surgical outcomes in older patients. $\mathrm{J} \mathrm{Am} \mathrm{Coll} \mathrm{Surg.}$ 2010;210(6):901-908. doi:10.1016/j.jamcollsurg.2010.01. 028

16. Saxton A, Velanovich V. Preoperative frailty and quality of life as predictors of postoperative complications. Ann Surg. 2011;253 (6):1223-1229. doi:10.1097/SLA.0b013e318214bce7

17. Fried LP, Tangen CM, Walston J, et al. Frailty in older adults: evidence for a phenotype. J Gerontol A Biol Sci Med Sci. 2001;56(3):M146-M156. doi:10.1093/gerona/56.3.m146

18. Rockwood $\mathrm{K}$, Song $\mathrm{X}$, MacKnight $\mathrm{C}$, et al. A global clinical measure of fitness and frailty in elderly people. CMAJ. 2005;173 (5):489-495. doi:10.1503/cmaj.050051

19. Rodriguez-Manas L, Feart C, Mann G, et al. Searching for an operational definition of frailty: a Delphi method based consensus statement: the frailty operative definition-consensus conference project. J Gerontol A Biol Sci Med Sci. 2013;68(1):62-67. doi:10.1093/gerona/gls119
20. Morley JE, Vellas B, van Kan GA, et al. Frailty consensus: a call to action. J Am Med Dir Assoc. 2013;14(6):392-397. doi:10. 1016/j.jamda.2013.03.022

21. Maggio M, Cappola AR, Ceda GP, et al. The hormonal pathway to frailty in older men. J Endocrinol Invest. 2005;28(11 Suppl Proceedings): $15-19$.

22. de Vries NM, Staal JB, van Ravensberg CD, Hobbelen JS, Olde Rikkert MG, Nijhuis-van der Sanden MW. Outcome instruments to measure frailty: a systematic review. Ageing Res Rev. 2011;10 (1):104-114. doi:10.1016/j.arr.2010.09.001

23. Rockwood K, Andrew M, Mitnitski A. A comparison of two approaches to measuring frailty in elderly people. $J$ Gerontol A Biol Sci Med Sci. 2007;62(7):738-743. doi:10.1093/gerona/ 62.7.738

24. Arya S, Kim SI, Duwayri Y, et al. Frailty increases the risk of 30-day mortality, morbidity, and failure to rescue after elective abdominal aortic aneurysm repair independent of age and comorbidities. J Vasc Surg. 2015;61(2):324-331. doi:10.1016/j.jvs.20 14.08.115

25. Ehlert BA, Najafian A, Orion KC, Malas MB, Black JH 3rd, Abularrage CJ. Validation of a modified frailty index to predict mortality in vascular surgery patients. J Vasc Surg. 2016;63 (6):1595-1601.e1592. doi:10.1016/j.jvs.2015.12.023

26. Karam J, Tsiouris A, Shepard A, Velanovich V, Rubinfeld I. Simplified frailty index to predict adverse outcomes and mortality in vascular surgery patients. Ann Vasc Surg. 2013;27(7):904-908. doi:10.1016/j.avsg.2012.09.015

27. Brahmbhatt R, Brewster LP, Shafii S, et al. Gender and frailty predict poor outcomes in infrainguinal vascular surgery. J Surg Res. 2016;201(1):156-165. doi:10.1016/j.jss.2015.10.026

28. Melin AA, Schmid KK, Lynch TG, et al. Preoperative frailty risk analysis index to stratify patients undergoing carotid endarterectomy. $J$ Vasc Surg. 2015;61(3):683-689. doi:10.1016/j.jvs.2014.10.009

29. Ambler GK, Brooks DE, Al Zuhir N, et al. Effect of frailty on short- and mid-term outcomes in vascular surgical patients. $\mathrm{Br} J$ Surg. 2015;102(6):638-645. doi:10.1002/bjs.9785

30. Srinivasan A, Ambler GK, Hayes PD, et al. Premorbid function, comorbidity, and frailty predict outcomes after ruptured abdominal aortic aneurysm repair. J Vasc Surg. 2016;63(3):603-609. doi:10.1016/j.jvs.2015.09.002

31. Easterlin MC, Chang DC, Wilson SE. A practical index to predict 30-day mortality after major amputation. Ann Vasc Surg. 2013;27 (7):909-917. doi:10.1016/j.avsg.2012.06.030

32. Partridge JSL, Fuller M, Harari D, Taylor PR, Martin FC, Dhesi JK. Frailty and poor functional status are common in arterial vascular surgical patients and affect postoperative outcomes. Int $J$ Surg. 2015;18:57-63. doi:10.1016/j.ijsu.2015.04.037

33. Arya S, Long CA, Brahmbhatt $\mathrm{R}$, et al. Preoperative frailty increases risk of nonhome discharge after elective vascular surgery in home-dwelling patients. Ann Vasc Surg. 2016;35:19-29. doi:10.1016/j.avsg.2016.01.052

34. Ali TZ, Lehman EB, Aziz F. Modified frailty index can be used to predict adverse outcomes and mortality after lower extremity bypass surgery. Ann Vasc Surg. 2017. doi:10.1016/j.avsg.2017.03.155

35. Scarborough JE, Bennett KM, Englum BR, Pappas TN, LagooDeenadayalan SA. The impact of functional dependency on outcomes after complex general and vascular surgery. Ann Surg. 2015;261(3):432-437. doi:10.1097/SLA.0000000000000767

36. Lee JS, He K, Harbaugh CM, et al. Frailty, core muscle size, and mortality in patients undergoing open abdominal aortic aneurysm repair. J Vasc Surg. 2011;53(4):912-917. doi:10.1016/j.jvs.2010. 10.111

37. Drudi LM, Phung K, Ades M, et al. Psoas muscle area predicts allcause mortality after endovascular and open aortic aneurysm repair. Eur J Vasc Endovasc Surg. 2016;52(6):764-769. doi:10. 1016/j.ejvs.2016.09.011 
38. Thiede R, Toosizadeh N, Mills JL, Zaky M, Mohler J, Najafi B. Gait and balance assessments as early indicators of frailty in patients with known peripheral artery disease. Clin Biomech (Bristol, Avon). 2016;32:1-7. doi:10.1016/j.clinbiomech.2015.12.002

39. Toosizadeh N, Stocker H, Thiede R, Mohler J, Mills JL, Najafi B. Alterations in gait parameters with peripheral artery disease: the importance of pre-frailty as a confounding variable. Vasc Med. 2016;21(6):520-527. doi:10.1177/1358863X16660626

40. Morisaki K, Yamaoka T, Iwasa K, Ohmine T. Influence of frailty on treatment outcomes after revascularization in patients with critical limb ischemia. J Vasc Surg. 2017. doi:10.1016/j.jvs.2017.04.048

41. Jeon-Slaughter H, Tsai S, Kamath P, Shammas NW, Brilakis ES, Banerjee S. Comparison of lower extremity endovascular intervention outcomes in women versus men. Am J Cardiol. 2017;119 (3):490-496. doi:10.1016/j.amjcard.2016.10.011

42. Hayashi K, Kobayashi K, Shimizu M, et al. Self-efficacy is an independent predictor for postoperative six-minute walk distance after elective open repair of abdominal aortic aneurysm. Disabil Rehabil. 2017;40(10):1114-1118. doi:10.1080/ 09638288.2017.1287962

43. O'Neill BR, Batterham AM, Hollingsworth AC, Durrand JW, Danjoux GR. Do first impressions count? Frailty judged by initial clinical impression predicts medium-term mortality in vascular surgical patients. Anaesthesia. 2016;71(6):684-691. doi:10.1111/ anae. 13404

44. McRae PJ, Walker PJ, Peel NM, et al. Frailty and geriatric syndromes in vascular surgical ward patients. Ann Vasc Surg. 2016;35:9-18. doi:10.1016/j.avsg.2016.01.033

45. Donald GW, Ghaffarian AA, Isaac F, et al. Preoperative frailty assessment predicts loss of independence after vascular surgery. $J$ Vasc Surg. 2018;68(5):1382-1389. doi:10.1016/j.jvs.2018.02.044

46. Lin H-S, Watts JN, Peel NM, Hubbard RE. Frailty and post-operative outcomes in older surgical patients: a systematic review. $B M C$ Geriatr. 2016;16(1):157. doi:10.1186/s12877-016-0329-8

47. Searle SD, Mitnitski A, Gahbauer EA, Gill TM, Rockwood K. A standard procedure for creating a frailty index. BMC Geriatr. 2008;8:24. doi:10.1186/1471-2318-8-24

48. Ganapathi AM, Englum BR, Hanna JM, et al. Frailty and risk in proximal aortic surgery. J Thorac Cardiovasc Surg. 2014;147 (1):186-191.e181. doi:10.1016/j.jtcvs.2013.09.011

49. van Netten JJ, Fortington LV, Hinchliffe RJ, Hijmans JM. Early post-operative mortality after major lower limb amputation: a systematic review of population and regional based studies. Eur J Vasc Endovasc Surg. 2016;51(2):248-257. doi:10.1016/j.ejvs. 2015.10.001

50. Binder EF, Schechtman KB, Ehsani AA, et al. Effects of exercise training on frailty in community-dwelling older adults: results of a randomized, controlled trial. J Am Geriatr Soc. 2002;50(12):19211928. doi:10.1046/j.1532-5415.2002.50601.x

51. Theou O, Stathokostas L, Roland KP, et al. The effectiveness of exercise interventions for the management of frailty: a systematic review. J Aging Res. 2011;2011:569194. doi:10.4061/2011/569 194

52. Kim DH, Kim CA, Placide S, Lipsitz LA, Marcantonio ER. Preoperative frailty assessment and outcomes at 6 months or later in older adults undergoing cardiac surgical procedures: a systematic review. Ann Intern Med. 2016;165(9):650-660. doi:10.7326/M160652

53. Fairhall N, Aggar C, Kurrle SE, et al. Frailty Intervention Trial (FIT). BMC Geriatr. 2008;8:27. doi:10.1186/1471-2318-8-27

54. Chen X, Mao G, Leng SX. Frailty syndrome: an overview. Clin Interv Aging. 2014;9:433-441. doi:10.2147/CIA.S45300

55. Mark DB, Shaw L, Harrell FE Jr, et al. Prognostic value of a treadmill exercise score in outpatients with suspected coronary artery disease. $N$ Engl $J$ Med. 1991;325(12):849-853. doi:10. 1056/NEJM199109193251204
56. Ross R, Blair SN, Arena R, et al. Importance of assessing cardiorespiratory fitness in clinical practice: a case for fitness as a clinical vital sign: a scientific statement from the American Heart Association. Circulation. 2016;134(24):e653-e699. doi:10.1161/ CIR.0000000000000461

57. Forman DE, Myers J, Lavie CJ, Guazzi M, Celli B, Arena R. Cardiopulmonary exercise testing: relevant but underused. Postgrad Med. 2010;122(6):68-86. doi:10.3810/pgm.2010.11.2225

58. Garner KK, Pomeroy W, Arnold JJ. Exercise stress testing: indications and common questions. Am Fam Physician. 2017;96(5):293299.

59. Sgura FA, Kopecky SL, Grill JP, Gibbons RJ. Supine exercise capacity identifies patients at low risk for perioperative cardiovascular events and predicts long-term survival. Am J Med. 2000;108 (4):334-336. doi:10.1016/s0002-9343(99)00465-9

60. Nugent AM, Riley M, Megarry J, O'Reilly MJ, MacMahon J, Lowry R. Cardiopulmonary exercise testing in the pre-operative assessment of patients for repair of abdominal aortic aneurysm. Ir $J$ Med Sci. 1998;167(4):238-241. doi:10.1007/bf02937421

61. Troisi N, Dorigo W, Lo Sapio P, et al. Preoperative cardiac assessment in patients undergoing aortic surgery: analysis of factors affecting the cardiac outcomes. Ann Vasc Surg. 2010;24(6):733740. doi:10.1016/j.avsg.2010.01.009

62. Hollingsworth A, Danjoux G, Howell SJ. Cardiopulmonary exercise testing before abdominal aortic aneurysm surgery: a validated risk prediction tool? Br J Anaesth. 2015;115(4):494-497. doi:10. 1093/bja/aev150

63. Myers J, Powell A, Smith K, Fonda H, Dalman RL. Cardiopulmonary exercise testing in small abdominal aortic aneurysm: profile, safety, and mortality estimates. Eur J Cardiovasc Prev Rehabil. 2011;18 (3):459-466. doi:10.1177/1741826710389384

64. Grant SW, Hickey GL, Wisely NA, et al. Cardiopulmonary exercise testing and survival after elective abdominal aortic aneurysm repairdagger. $B r J$ Anaesth. 2015;114(3):430-436. doi:10.1093/ bja/aeu383

65. Barakat HM, Shahin Y, McCollum PT, Chetter IC. Prediction of organ-specific complications following abdominal aortic aneurysm repair using cardiopulmonary exercise testing. Anaesthesia. 2015;70(6):679-685. doi:10.1111/anae.12986

66. Fleisher LA, Fleischmann KE, Auerbach AD, et al. 2014 ACC/AHA guideline on perioperative cardiovascular evaluation and management of patients undergoing noncardiac surgery: executive summary: a report of the American College of Cardiology/American Heart Association Task Force on practice guidelines. Circulation. 2014;130(24):2215-2245. doi:10.1161/CIR.0000000000000105

67. Zarinsefat A, Henke P. Update in preoperative risk assessment in vascular surgery patients. J Vasc Surg. 2015;62(2):499-509. doi:10.1016/j.jvs.2015.05.031

68. Abir F, Kakisis I, Sumpio B. Do vascular surgery patients need a cardiology work-up? A review of pre-operative cardiac clearance guidelines in vascular surgery. Eur J Vasc Endovasc Surg. 2003;25 (2):110-117. doi:10.1053/ejvs.2002.1797

69. Cuocolo A, Acampa W, Imbriaco M, De Luca N, Iovino GL, Salvatore M. The many ways to myocardial perfusion imaging. $Q$ J Nucl Med Mol Imaging. 2005;49(1):4-18.

70. Stojanovic MD, Markovic DZ, Vukovic AZ, et al. Enhanced recovery after vascular surgery. Front Med. 2018;5:2. doi:10. 3389/fmed.2018.00002

71. Peacock MR, Farber A, Eslami MH, et al. Hypoalbuminemia predicts perioperative morbidity and mortality after infrainguinal lower extremity bypass for critical limb ischemia. Ann Vasc Surg. 2017;41:169-175.e164. doi:10.1016/j.avsg.2016.08.043

72. Casey J, Flinn WR, Yao JS, Fahey V, Pawlowski J, Bergan JJ. Correlation of immune and nutritional status with wound complications in patients undergoing vascular operations. Surgery. 1983;93 (6):822-827. 
73. Abdullah HR, Lien VP, Ong HK, et al. Protocol for a single-centre, randomised controlled study of a preoperative rehabilitation bundle in the frail and elderly undergoing abdominal surgery. BMJ Open. 2017;7(8):e016815. doi:10.1136/bmjopen-2017-016815

74. Durkin MT, Mercer KG, McNulty MF, et al. Vascular surgical society of great britain and ireland: contribution of malnutrition to postoperative morbidity in vascular surgical patients. Br J Surg. 1999;86(5):702. doi:10.1046/j.1365-2168.1999.0702a.x

75. van Zanten AR. Nutrition barriers in abdominal aortic surgery: a multimodal approach for gastrointestinal dysfunction. JPEN J Parenter Enteral Nutr. 2013;37(2):172-177. doi:10.1177/01486 07112464499

76. Wohlauer M, Brier C, Kuramochi Y, Eagleton M. Preoperative hypoalbuminemia is a risk factor for early and late mortality in patients undergoing endovascular juxtarenal and thoracoabdominal aortic aneurysm repair. Ann Vasc Surg. 2017;42:198-204. doi:10.1016/j.avsg.2017.03.058

77. Inagaki E, Farber A, Eslami MH, et al. Preoperative hypoalbuminemia is associated with poor clinical outcomes after open and endovascular abdominal aortic aneurysm repair. J Vasc Surg. 2017;66(1):53-63.e51. doi:10.1016/j.jvs.2016.10.110

78. Boitano LT, Wang EC, Kibbe MR. Differential effect of nutritional status on vascular surgery outcomes in a veterans affairs versus private hospital setting. Am J Surg. 2012;204(5):e27-e37. doi:10.1016/j.amjsurg.2012.07.023

79. Gotlib Conn L, Rotstein OD, Greco E, et al. Enhanced recovery after vascular surgery: protocol for a systematic review. Syst Rev. 2012;1:52. doi:10.1186/2046-4053-1-52

80. Svanfeldt M, Thorell A, Hausel J, Soop M, Nygren J, Ljungqvist O. Effect of "preoperative" oral carbohydrate treatment on insulin action - a randomised cross-over unblinded study in healthy subjects. Clin Nutr. 2005;24(5):815-821. doi:10.1016/j.clnu.2005.05.002

81. Travers J, Romero-Ortuno R, Bailey J, Cooney MT. Delaying and reversing frailty: a systematic review of primary care interventions. Br J Gen Pract. 2018.

82. Barakat HM, Shahin Y, Khan JA, McCollum PT, Chetter IC. Preoperative supervised exercise improves outcomes after elective abdominal aortic aneurysm repair: a randomized controlled trial. Ann Surg. 2016;264(1):47-53. doi:10.1097/SLA.0000000000001609

83. Tew GA, Weston M, Kothmann E, et al. High-intensity interval exercise training before abdominal aortic aneurysm repair (HITAAA): protocol for a randomised controlled feasibility trial. BMJ Open. 2014;4(1):e004094-e04094. doi:10.1136/bmjopen-2013004094

84. Heatherton TF, Kozlowski LT, Frecker RC, Fagerstrom KO. The fagerstrom test for nicotine dependence: a revision of the fagerstrom tolerance questionnaire. Br J Addict. 1991;86(9):1119-1127. doi:10.1111/j.1360-0443.1991.tb01879.x

85. Wallaert JB, Newhall KA, Suckow BD, et al. Relationships between 2-year survival, costs, and outcomes following carotid endarterectomy in asymptomatic patients in the vascular quality initiative. Ann Vasc Surg. 2016;35:174-182. doi:10.1016/j.avsg. 2016.01.024

86. McPhee JT, Nguyen LL, Ho KJ, Ozaki CK, Conte MS, Belkin M. Risk prediction of 30-day readmission after infrainguinal bypass for critical limb ischemia. J Vasc Surg. 2013;57(6):1481-1488. doi:10.1016/j.jvs.2012.11.074

87. Hicks CW, Bronsert M, Hammermeister KE, et al. Operative variables are better predictors of postdischarge infections and unplanned readmissions in vascular surgery patients than patient characteristics. J Vasc Surg. 2017;65(4):1130-1141.e1139. doi:10. 1016/j.jvs.2016.10.086

88. Smeds MR, Privratsky A, Thrush CR, et al. Nicotine dependence and willingness to quit smoking in vascular surgery patients. Ann Vasc Surg. 2017;45:144-153. doi:10.1016/j.avsg.2017.06.049
89. Newhall K, Suckow B, Spangler E, et al. Impact and duration of brief surgeon-delivered smoking cessation advice on attitudes regarding nicotine dependence and tobacco harms for patients with peripheral arterial disease. Ann Vasc Surg. 2017;38:113-121. doi:10.1016/j.avsg.2016.06.005

90. Goodney PP, Spangler EL, Newhall K, et al. Feasibility and pilot efficacy of a brief smoking cessation intervention delivered by vascular surgeons in the Vascular Physician Offer and Report (VAPOR) trial. J Vasc Surg. 2017;65(4):1152-1160.e1152. doi:10.1016/j.jvs.2016.10.121

91. van den Berghe G, Wouters P, Weekers F, et al. Intensive insulin therapy in critically ill patients. N Engl J Med. 2001;345(19):13591367. doi:10.1056/NEJMoa011300

92. Malmstedt J, Wahlberg E, Jorneskog G, Swedenborg J. Influence of perioperative blood glucose levels on outcome after infrainguinal bypass surgery in patients with diabetes. Br J Surg. 2006;93 (11):1360-1367. doi:10.1002/bjs.5466

93. Serio S, Clements JM, Grauf D, Merchant AM. Outcomes of diabetic and nondiabetic patients undergoing general and vascular surgery. ISRN Surg. 2013;2013:963930. doi:10.1155/2013/963930

94. van Kuijk JP, Dunkelgrun M, Schreiner F, et al. Preoperative oral glucose tolerance testing in vascular surgery patients: long-term cardiovascular outcome. Am Heart J. 2009;157(5):919-925. doi:10.1016/j.ahj.2009.02.011

95. Arya S, Binney ZO, Khakharia A, et al. High hemoglobin A1c associated with increased adverse limb events in peripheral arterial disease patients undergoing revascularization. J Vasc Surg. 2018;67 (1):217-228.e211. doi:10.1016/j.jvs.2017.06.101

96. Al-Thani H, El-Matbouly M, Al-Sulaiti M, Al-Thani N, Asim M, El-Menyar A. Does perioperative hemoglobin A1c level affect the incidence, pattern and mortality of lower extremity amputation? Curr Vasc Pharmacol. 2019;11(6):466-476. doi:10.1111/17530407.12873

97. Goldman MP, Clark CJ, Craven TE, et al. Effect of intensive glycemic control on risk of lower extremity amputation. J Am Coll Surg. 2018;227(6):596-604. doi:10.1016/j.jamcollsurg.2018.09.021

98. Showen A, Russell TA, Young S, Gupta S, Gibbons MM. Hyperglycemia is associated with surgical site infections among general and vascular surgery patients. Am Surg. 2017;83(10): 1108-1111.

99. Hjellestad ID, Softeland E, Husebye ES, Jonung T. HbA1c predicts long-term postoperative mortality in patients with unknown glycemic status at admission for vascular surgery: an exploratory study. $J$ Diabetes. 2018;11(6):466-476. doi:10.1111/1753-0407.12873

100. van Steen SC, Woodward M, Chalmers J, et al. Haemoglobin glycation index and risk for diabetes-related complications in the Action in Diabetes and Vascular Disease: Preterax and Diamicron Modified Release Controlled Evaluation (ADVANCE) trial. Diabetologia. 2018;61(4):780-789. doi:10.1007/s00125-0174539-1

101. Kristensen KL, Dahl M, Rasmussen LM, Lindholt JS. Glycated hemoglobin is associated with the growth rate of abdominal aortic aneurysms: a substudy from the VIVA (Viborg Vascular) randomized screening trial. Arterioscler Thromb Vasc Biol. 2017;37 (4):730-736. doi:10.1161/ATVBAHA.116.308874

102. Muehling B, Schelzig H, Steffen P, Meierhenrich R, Sunder-Plassmann L, Orend KH. A prospective randomized trial comparing traditional and fast-track patient care in elective open infrarenal aneurysm repair. World J Surg. 2009;33(3):577585. doi:10.1007/s00268-008-9892-2

103. Crimi E, Hill CC. Postoperative ICU management of vascular surgery patients. Anesthesiol Clin. 2014;32(3):735-757. doi:10.10 16/j.anclin.2014.05.001 
104. Gene Huguet L, Navarro Gonzalez M, Kostov B, et al. Pre frail 80: multifactorial intervention to prevent progression of pre-frailty to frailty in the elderly. $J$ Nutr Health Aging. 2018;22(10):1266-1274. doi:10.1007/s12603-018-1089-2

105. Drudi LM, Tat J, Ades M, et al. Preoperative exercise rehabilitation in cardiac and vascular interventions. J Surg Res. 2019;237:3-11. doi:10.1016/j.jss.2018.11.042

106. Ellis G, Gardner M, Tsiachristas A, et al. Comprehensive geriatric assessment for older adults admitted to hospital. Cochrane Database Syst Rev. 2017;9:Cd006211.
107. McIsaac DI, Beaule PE, Bryson GL, Van Walraven C. The impact of frailty on outcomes and healthcare resource usage after total joint arthroplasty: a population-based cohort study. Bone Joint J. 2016;98-b(6):799-805. doi:10.1302/0301620X.98B6.37124

108. Moher D, Liberati A, Tetzlaff J, Altman DG. Preferred reporting items for systematic reviews and meta-analyses: the PRISMA statement. PLoS Med. 2009;6(7):e1000097. doi:10.1371/journal.pmed.1000097

\section{Publish your work in this journal}

Therapeutics and Clinical Risk Management is an international, peerreviewed journal of clinical therapeutics and risk management, focusing on concise rapid reporting of clinical studies in all therapeutic areas, outcomes, safety, and programs for the effective, safe, and sustained use of medicines. This journal is indexed on PubMed Central, CAS,
EMBase, Scopus and the Elsevier Bibliographic databases. The manuscript management system is completely online and includes a very quick and fair peer-review system, which is all easy to use. Visit http://www.dovepress.com/testimonials.php to read real quotes from published authors. 